\section{SERIES "THE GENETIC AND CARDIOVASCULAR ASPECTS OF OBSTRUCTIVE SLEEP APNOEA/HYPOPNOEA SYNDROME”' Edited by R.L. Riha and W.T. McNicholas Number 4 in this Series}

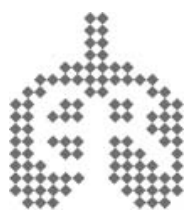

\title{
Cardiovascular disease in obstructive sleep apnoea syndrome: the role of intermittent hypoxia and inflammation
}

\author{
J.F. Garvey*,\#, C.T. Taylor" and W.T. McNicholas*,\#
}

ABSTRACT: There is increasing evidence that intermittent hypoxia plays a role in the development of cardiovascular risk in obstructive sleep apnoea syndrome (OSAS) through the activation of inflammatory pathways. The development of translational models of intermittent hypoxia has allowed investigation of its role in the activation of inflammatory mechanisms and promotion of cardiovascular disease in OSAS. There are noticeable differences in the response to intermittent hypoxia between body tissues but the hypoxia-sensitive transcription factors hypoxia-inducible factor-1 and nuclear factor-кВ appear to play a key role in mediating the inflammatory and cardiovascular consequences of OSAS. Expanding our understanding of these pathways, the cross-talk between them and the activation of inflammatory mechanisms by intermittent hypoxia in OSAS will provide new avenues of therapeutic opportunity for the disease.

KEYWORDS: Cardiovascular disease, inflammation, hypoxia, nuclear factor-кB, obstructive sleep apnoea syndrome, review

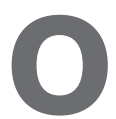

bstructive sleep apnoea syndrome (OSAS) is a highly prevalent disorder characterised by repetitive upper airway obstruction during sleep that leads to intermittent hypoxia, sleep fragmentation and excessive daytime sleepiness. Over the past 30 yrs our understanding of the features and consequences of this sleep-disordered breathing has progressed significantly and it is now recognised as a major healthcare problem affecting $\geqslant 4 \%$ of males and $\geqslant 2 \%$ of females in the developed world [1]. Given the modern pandemic of obesity in Western society, the prevalence of this disorder will probably continue to rise.

Recent studies have shown that OSAS is associated with an increase in all-cause and cardiovascular mortality, complementing existing evidence that OSAS has a causal relationship in the development of cardiovascular disease [2, 3]. The data are strongest for systemic arterial hypertension, with a number of large population-based studies showing an association between OSAS and development of systemic hypertension, independent of confounding factors such as sex, age and obesity [4, 5]. There are also studies supporting an independent association with ishaemic heart disease, atrial fibrillation, stroke and heart failure, and long-term follow-up studies of OSAS patients effectively treated with continuous positive airway presure (CPAP) have shown a significant benefit in reducing cardiovascular mortality and nonfatal cardiovascular events [6-11].

The pathogenesis of cardiovascular disease in OSAS is not completely understood, but is thought to be multifactorial in origin [12]. Proposed mechanisms by which OSAS predisposes to cardiovascular disease include sympathetic excitation, vascular endothelial dysfunction and metabolic dysregulation, as well as oxidative stress and inflammation induced by cyclical

Previous articles in this series: No. 1: MacLeod AK, Liewald DCM, McGilchrist MM, Morris AD, Kerr SM, Porteous DJ. Some principles and practices of genetic biobanking studies. Eur Respir J 2009; 33: 419-425. No. 2: Riha RL, Gislasson T, Diefenbach K. The phenotype and genotype of adult obstructive sleep apnoea/hypopnoea syndrome. Eur Respir J 2009; 33: 646-655. No. 3: Jennum P, Riha RL. Epidemiology of sleep apnoea/hypopnoea syndrome and sleepdisordered breathing. Eur Respir J 2009; 33: 907-914.

AFFILIATIONS

*Respiratory Sleep Disorders Unit, St Vincent's University Hospital, and \# UCD Conway Institute of Biomolecular and Biomedical Research, University College Dublin, Dublin, Ireland.

CORRESPONDENCE

W.T. McNicholas

Respiratory Sleep Disorders Unit

St. Vincent's University Hospital

Elm Park

Dublin 4

Ireland

Fax: 35312697949

E-mail: walter.mcnicholas@ucd.ie

Received:

July 212008

Accepted after revision:

December 072008

STATEMENT OF INTEREST

None declared.
European Respiratory Journal Print ISSN 0903-1936 Online ISSN 1399-3003 
intermittent hypoxia [13]. There is increasing evidence that intermittent hypoxia plays a role in the pathobiology of cardiovascular complications in OSAS through activation of pro-inflammatory pathways (fig. 1) [14]. The development of cell culture and animal models of intermittent hypoxia in recent years have allowed investigation of the role of intermittent hypoxia in the activation of inflammatory mechanisms and development of atherosclerosis in OSAS.

The present manuscript highlights the role of intermittent hypoxia in the pathophysiology of cardiovascular complications in OSAS through activation of pro-inflammatory pathways. The hypoxia-sensitive transcription factors that probably contribute to the inflammatory and cardiovascular consequences of intermittent hypoxia are discussed. There is a review of the data garnered from translational studies involving cell culture and animal models of intermittent hypoxia, which complement data from studies of OSAS patients. The effects of intermittent hypoxia in specific tissue types are explored, with the aim of identifying the target organs of intermittent hypoxia in OSAS. The therapeutic potential of targetting inflammatory mechanisms in the treatment of OSAS is also reviewed.

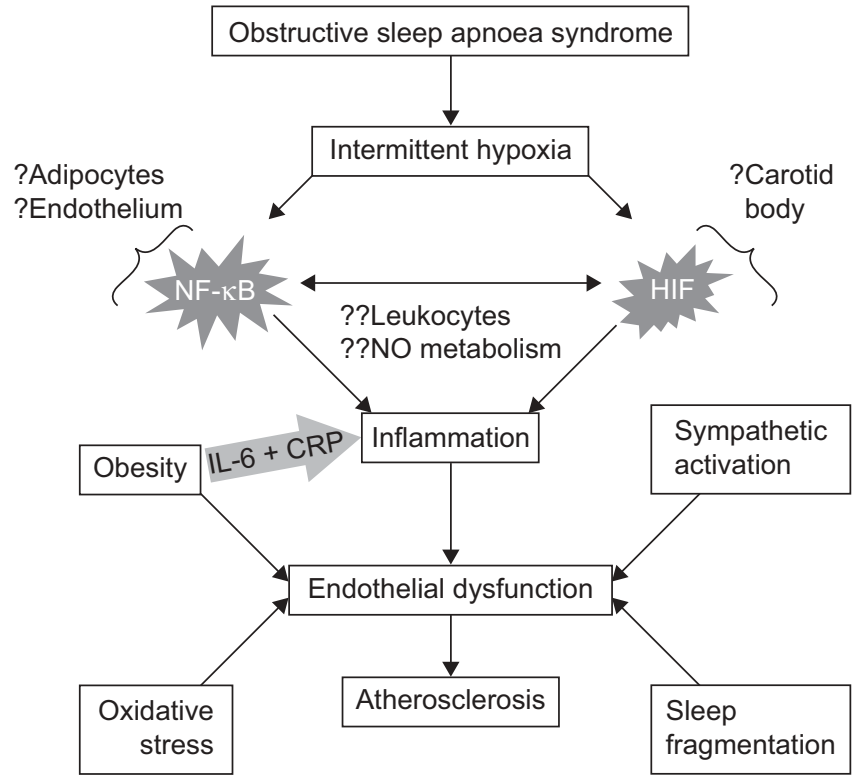

FIGURE 1. Activation and interaction of inflammatory pathways in response to intermittent hypoxia in obstructive sleep apnoea syndrome (OSAS). Proposed mechanisms by which OSAS predisposes to the development of endothelial dysfunction and cardiovascular disease include sympathetic excitation, vascular endothelial dysfunction, oxidative stress and inflammation. Intermittent hypoxia, the characteristic feature of OSAS, activates inflammatory mechanisms directly through the hypoxia-sensitive transcription factors nuclear factor (NF)-kB and hypoxiainducible factor (HIF)-1. The co-existence of obesity in many OSAS patients augments the pro-inflammatory state through increased production of interleukin (IL)-6 and C-reactive protein (CRP) by adipose tissue. There are differences in the response to intermittent hypoxia between body tissues, with NF-KB having its largest apparent influence in endothelial cells, and adipocytes and HIF-1 playing a key role in the carotid body response. Activation of leukocytes and nitric oxide (NO) involvement in the inflammatory response to intermittent hypoxia in OSAS may be regulated by cross-talk between the NF-kB and HIF-1 pathways.

\section{PATTERNS OF INTERMITTENT HYPOXIA}

OSAS is characterised by a unique form of intermittent hypoxia, with short, repetitive cycles of hypoxia and reoxygenation. However, patterns of cyclical intermittent hypoxia are not uniform across all patients with OSAS or in translational models of the disease. For example, rapid eye movement (REM) sleep is associated with longer apnoeas and greater apnoea-related desaturation than non-REM sleep [15], which may predispose some patients to having periods of sustained hypoxia in REM sleep, during which oxygen saturation fails to return to baseline in between apnoeas. This is an important point for consideration when examining the pathobiological effects of OSAS, particularly in translational studies, as prolonged periods of sustained hypoxia allow for development of an adaptive response aimed at increasing tissue perfusion and oxygenation, whereas shorter intermittent hypoxic exposures may preferentially activate inflammatory pathways [16].

A number of studies have indicated such an adaptive response in patients with more severe OSAS-related nocturnal hypoxaemia. CAHAN and co-workers $[17,18]$ noted a marked increase in the variability of erythropoietin (EPO) levels in OSAS patients and suggested that mean EPO levels are in part related to the presence of OSAS, the degree of hypoxaemia, and body weight. WINNICKI et al. [19] showed similar EPO levels in patients with OSAS and healthy controls, but EPO levels increased in patients with severe OSAS during sleep and were decreased with CPAP therapy. EPO levels remained stable in patients with mild disease throughout the night. IMAGAWA et al. [20] found an increase in haemoglobin concentration, an increase in serum EPO levels and a marked increase in serum vascular endothelial growth factor (VEGF) levels in patients with severe OSAS. ScHUlz et al. [21] showed that OSAS patients with severe nocturnal hypoxia had markedly increased VEGF serum levels compared with OSAS patients presenting with moderate hypoxia and the control subjects. LAVIE et al. [22] showed a similar elevation in VEGF concentration in sleep apnoea patients with a mean apnoea/hypopnoea index of 53.4 events $\cdot \mathrm{h}^{-1}$.

The induction of protective responses in a subset of OSAS patients may also partly explain the decline in mortality risk associated with OSAS in those aged $>50$ yrs [23]. In the largest study to date, excess mortality was associated with OSAS only in males aged $<50$ yrs [24]. This trend was apparent even in patients with severe OSAS (respiratory disturbance index $>50$ ), the majority of whom were also obese with a mean body mass index (BMI) of $32.8 \mathrm{~kg} \cdot \mathrm{m}^{-2}$. Similar findings have been reported in other mortality studies in OSAS [25-27]. Although the cyclical intermittent hypoxia that characterises OSAS may not provide sufficient hypoxic stimulus to induce cardioprotection through ischaemic preconditioning, periods of sustained hypoxia during REM sleep in a subset of OSAS patients, as described above, at least theoretically, have the scope to induce such a phenomenon.

A variety of cell culture, animal and human models of intermittent hypoxia have been developed as tools to investigate its role in the pathophysiology of OSAS [28]. However, despite seeking to mimic the cyclical variation in oxygenation seen in OSAS, models vary in terms of duration of hypoxic exposure, the number of hypoxic episodes and the degree of 
hypoxia experienced. Therefore, it is important to note that these are generally models of intermittent hypoxia rather than models of OSAS. Cell culture models are relatively low cost, are not labour intensive and allow investigation of multiple cell types, but the severity of hypoxia is usually far greater than that experienced in OSAS. Animal models better imitate the pattern of intermittent hypoxia in OSAS and the use of transgenic animals allows investigation of the possible effects of specific genes in the pathophysiology of the disorder. However, hypoxic events in animal models are usually not linked to sleep state and are not accompanied by sleep fragmentation and the arousals that are typical in OSAS. Most animal models are based on systems that cyclically alter the fraction of inspired oxygen to mimic the intermittent hypoxia in OSAS, and are therefore not accompanied by upper airway occlusion and the changes in intrathoracic pressure associated with apnoea. Nonetheless, translational models of intermittent hypoxia are now essential tools in the investigation of disease mechanisms specific to OSAS, and complement clinical studies which are often confounded by the presence of comorbidities in the patient population.

\section{INFLAMMATION IN OSAS: CYTOKINES AND INFLAMMATORY CELLS}

The evidence for a direct role of OSAS in the regulation of inflammation is strongest for tumour necrosis factor (TNF)- $\alpha$. Several studies have demonstrated elevated TNF- $\alpha$ levels in OSAS patients and, although both T-cells and monocytes have been identified as potential sources in OSAS patients, it should be remembered that the endothelium and adipose tissue can also secrete TNF- $\alpha$. A four-fold increase in the percentage of $\gamma \delta$ T-cells containing intracellular TNF- $\alpha$ was observed by Dyugovskaya et al. [29]. MinOguchi et al. [30] showed that spontaneous production of TNF- $\alpha$ by monocytes and serum levels of TNF- $\alpha$ are elevated in patients with moderate-to-severe OSAS and that these levels are decreased by CPAP therapy. VGONTZAS et al. [31] found that TNF- $\alpha$ levels were highest among patients with OSAS when compared with other subjects with conditions associated with excessive daytime somnolence (EDS), including narcolepsy and idiopathic hypersomnolence. It was proposed that TNF- $\alpha$ may mediate sleepiness in conditions of EDS, and a significant and marked decrease in objective sleepiness was subsequently demonstrated in eight obese OSAS patients following treatment with the TNF- $\alpha$ antagonist etanercept [32]. The propensity of TNF- $\alpha$ to mediate sleepiness was also observed in the largest study to date, by RYAN et al. [33], who showed that TNF- $\alpha$ levels were higher in sleepy nonapnoeic snorers compared with normal control subjects, but still lower than in subjects with OSAS. CPAP was also found to significantly lower TNF- $\alpha$ levels. Similarly, levels of interleukin (IL)-8 showed similar differences between groups and also fell after CPAP therapy. Importantly, all subjects in the study were matched in terms of age, BMI, blood pressure and lipid profile, were free of cardiovascular comorbidity and were not taking any medications. The inability of other studies to find similar elevations of TNF- $\alpha$ and IL- 8 levels in OSAS patients may be accounted for by the failure to control for confounding factors in this manner [34]. It should also be noted that, in the OSAS group, oximetry recordings during polysomnography demonstrated frequent transient oxygen desaturations during apnoeas with resaturation to normal levels in the periods between apnoea.

There is also evidence supporting the activation of circulating leukocytes in OSAS patients. Several studies have demonstrated upregulation of leukocyte adhesion molecule expression in OSAS [29, 35-39]. This increased expression of adhesion molecules is associated with increased avidity toward endothelial cells and a subsequent enhancement in inflammationmediated endothelial dysfunction. It has been shown that neutrophil apoptosis is delayed in OSAS patients, further augmenting their inflammatory potential [35].

In brief, intermittent hypoxia may directly promote cytokine production and inflammatory cell activation in OSAS patients. It should be noted, however, that only one study to date has shown a direct association between this inflammatory activation and vascular change [40]. The potential roles of two hypoxia-sensitive transcription factors in the regulation of this inflammatory response will be discussed in the following section.

\section{HYPOXIA-RESPONSIVE TRANSCRIPTION FACTORS IN OSAS \\ Nuclear factor- $\kappa B$}

The eukaryotic transcription factor nuclear factor (NF)- $\kappa B$ is a key mediator of the inflammatory response. NF- $\kappa B$ is composed of members of the Rel family of proteins and was first described as a nuclear factor necessary for immunoglobulin $\kappa$ light chain transcription in B-cells, hence its name [41]. NF- $\kappa$ B exists in most cells in an inactive form bound to the inhibitor, IкB, which retains it in the cytoplasm. I $\mathrm{B}$ is targeted for ubiquitinmediated degradation upon sensation of an appropriate endogenous or exogenous inflammatory stimulus [42]. NF- $\kappa \mathrm{B}$ is released from IкB and translocates to the nucleus, where it can upregulate transcription of specific pro-inflammatory genes responsible for encoding of inflammatory cytokines, chemokines and surface adhesion molecules. NF- $\kappa \mathrm{B}$ plays a central role in the inflammatory response and orchestrates expression of a range of factors, including cytokines (TNF- $\alpha$, IL-6 and IL-8), adhesion molecules (intercellular adhesion molecule-1) and enzymes (cyclo-oxygenase-2) [43-45].

There is evidence in the literature supporting an association between intermittent hypoxia in cell culture and animal models, and OSAS in humans, with increases in NF- $\kappa \mathrm{B}$ activity and its downstream products, particularly TNF- $\alpha$. In an in vitro model using HeLa cells and bovine aortic endothelial cells, intermittent hypoxia activated NF- $\kappa \mathrm{B}$ in a dose-dependent manner $[16,46]$. In another study, serum TNF- $\alpha$ levels were measured in OSAS patients and compared with levels in agesex- and BMI-matched controls [33]. Serum TNF- $\alpha$ levels were higher in OSAS patients compared with controls and reverted to control levels after 6 weeks of CPAP therapy. Similarly, in a mouse model, exposure to intermittent hypoxia activated $\mathrm{NF}-\kappa \mathrm{B}$ in cardiovascular tissue with a concomitant increase in expression of inducible nitric oxide synthase (iNOS) protein, a recognised NF- $\mathrm{B}$-dependent gene product. OSAS patients were also found to have markedly elevated monocyte NF- $\kappa B$ activity that decreased significantly with CPAP therapy [43]. The same group have also demonstrated increased NF- $\kappa B$ activity in circulating neutrophils and raised plasma levels of 
the NF-кB-controlled gene products, soluble E-selectin and soluble vascular cell adhesion molecule-1 in OSAS patients, with a reduction in NF- $\mathrm{kB}$ activity to control levels following CPAP therapy [47].

\section{Hypoxia-inducible factor-1}

Hypoxia-inducible factor (HIF)-1 is a heterodimeric transcription factor consisting of a constitutively expressed $\beta$-subunit and an $\alpha$-subunit that contains an oxygen-dependent degradation (ODD) domain [48]. Under normoxic cellular conditions, the ODD domain is hydroxylated in an oxygen-dependent manner, rendering the $\alpha$-subunit vulnerable to proteasomal degradation [49]. Therefore, HIF-1 is suppressed in normoxia. However, in hypoxia, HIF-1 is stable and active, capable of binding to the regulatory regions of its target genes and inducing their expression.

HIF-1 is the major regulator of oxygen homeostasis within the cell, affecting and regulating dozens of genes as cellular oxygen concentrations change. In general, such factors allow an adaptation to hypoxia that is directed towards increasing tissue perfusion and oxygenation and, hence, overcoming the initial hypoxic insult. In normoxia, most cells produce ATP via oxidative phosphorylation and HIF-1 regulates the shift to increased glycolysis and anaerobic metabolism at low oxygen tensions [50]. By binding to the hypoxia response element in the EPO gene, HIF-1 activates its transcription, increasing red blood cell production and enhancing blood oxygen-carrying capacity [51]. Through VEGF transcription, HIF-1 regulates migration of mature endothelial cells towards hypoxic areas of tissue, thereby promoting angiogenesis [52]. Elevated serum levels of HIF-1 gene products, such as EPO and VEGF, have been demonstrated in OSAS patients, particularly patients with severe nocturnal hypoxaemia [17-20]. Cell culture experiments have also shown upregulation of HIF-1 in intermittent hypoxia [53, 54].

However, not all HIF-1-mediated effects are protective. HIF-1 promotes enhanced survival of myeloid inflammatory cells, such as granulocytes, monocytes and macrophages, resulting in their functional longevity and potentiation of inflammation [55]. Therefore, HIF-1 may also be viewed as a pro-inflammatory contributor to the hypoxic response by promoting inflammatory cell survival. Delayed neutrophil apoptosis has recently been demonstrated in OSAS patients; however, the mechanisms that underlie this response remain unexplained [35].

\section{Interaction between the NF- $\kappa B$ and HIF-1 pathways}

It has become clear that, as well as having independent roles in the regulation of gene expression in response to hypoxia, there is also significant crosstalk between NF- $\mathrm{KB}$ and HIF-1, resulting in a mutual dependence between the pathways (fig. 2.) There is an active NF- $\mathrm{KB}$ binding site contained in the proximal promoter site of the HIF-1 gene and NF- $\mathrm{kB}$ regulates basal levels of HIF-1 gene expression [56, 57]. Hypoxia up-regulates HIF-1 transcription through a NF-kB-dependent mechanism [58]. Conversely, HIF-1 can also influence the NF-кB pathway. WALMSLEY et al. [59] showed that the hypoxic induction of NF$\kappa \mathrm{B}$ transcription is dependent on the presence of HIF- 1 and that HIF-1 is directly involved in regulating neutrophil survival in hypoxia through the modulation of NF- $\mathrm{kB}$ signalling. Overexpression of HIF-1 results in increased NF-KB activity and an enhanced inflammatory response [60]. HIF-1 and NF-кB also share some common gene products. For example, nitric oxide is a potent vasodilator, and both HIF-1 and NF- $\mathrm{kB}$ can enhance its bioavailability through increased expression of iNOS [61, 62]. In summary, it is likely that cross-talk between NF- $\mathrm{KB}$ and HIF-1 plays a central but complex role in modulating the inflammatory response to intermittent hypoxia in OSAS [63].

\section{DIFFERENTIAL RESPONSES TO INTERMITTENT HYPOXIA IN SPECIFIC TISSUE TYPES}

\section{Intermittent hypoxia and carotid bodies}

A number of physiological responses to hypoxia have been shown to depend on the oxygen-sensing ability of the peripheral arterial chemoreceptors, particularly the carotid bodies. For example, the role of peripheral arterial chemoreceptors in modulating ventilatory acclimatisation to altitude is well recognised [64]. Little is known about the effect of intermittent hypoxia on the carotid body in the context of OSAS. Physiological responses to intermittent hypoxia as it relates to altitude training differ significantly from responses to the characteristic cycles of intermittent hypoxia in OSAS [65]. The propensity for development of periodic breathing during sleep with increasing altitude is well recognised, but it should be acknowledged that normoxia generally follows apnoea at sea level in OSAS, whereas hypoxia persists after apnoea at high altitude [66]. In OSAS, the duration of hypoxic exposure is short but hypoxic episodes occur very frequently throughout the night. OSAS effects a chronic low-grade inflammatory state associated with endothelial dysfunction, whereas acclimatisation to altitude is associated with a protective effect on the vasculature, lowering blood pressure and reducing cardiovascular mortality [67, 68].

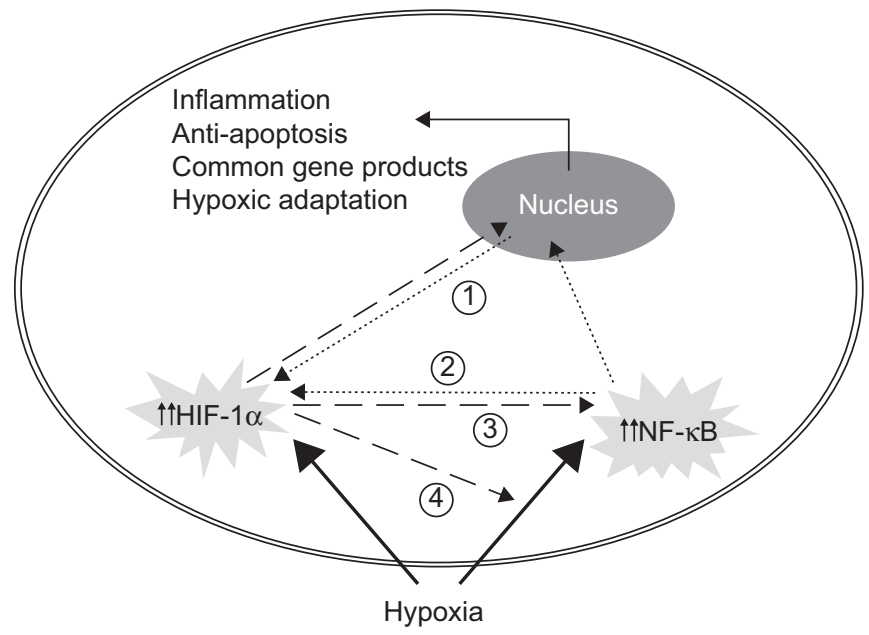

FIGURE 2. Interaction between hypoxia-inducible factor (HIF)-1 $\alpha$ and nuclear factor (NF)- $\mathrm{kB}$ in hypoxia. Tissue hypoxia leads to the activation of the transcription factors $\mathrm{HIF}-1 \alpha$ and NF- $\mathrm{KB}$. Activation of HIF- $1 \alpha$ facilitates an adaptive response to hypoxia, whereas upregulation of NF-kB leads to inflammatory and anti-apoptotic gene expression. HIF-1 $\alpha$ and NF-KB also share some gene products, e.g. inducible nitric oxide synthase. NF- $\mathrm{KB}$ regulates basal levels of HIF-1 gene expression and upregulation of HIF-1 transcription occurs through a NF- $\mathrm{kB}$-dependent mechanism (1 and 2). Conversely, hypoxic induction of NF- $\mathrm{kB}$ transcription is dependent on the presence of $\mathrm{HIF}-1 \alpha$ (3) and $\mathrm{HIF}-1 \alpha$ is directly involved in regulating apoptosis through the modulation of NF- $\mathrm{\kappa B}$ signalling (4) 
Thus, although a substantial body of data exists on the effects of sustained or prolonged periods of hypoxia on the carotid body, its relevance to OSAS largely remains to be determined [69]. It has been shown, however, that patients with OSAS have an exaggerated peripheral chemoreflex response to hypoxia, independent of the effect of obesity [70-72]. This may contribute to enhanced sympathetic activity, increased blood pressure and decreased baroreflex sensitivity in OSAS patients [73].

\section{In vitro studies}

There is a growing body of evidence supporting an essential role for the transcription factor HIF-1 $\alpha$ in oxygen sensing by the carotid body [74]. YUAN and co-workers [53, 54] showed that stabilisation of HIF- $1 \alpha$ occurs as a result of the increased generation of reactive oxygen species by reduced nicotinamide adenine dinucleotide phosphate oxidase in an in vitro model of intermittent hypoxia using PC12 rat phaeochromocytoma cells (30 s of hypoxia alternating with $4 \mathrm{~min}$ of reoxygenation). These cells share similar properties with carotid body glomus cells, including expression of tyrosine hydroxylase, the ratelimiting enzyme for catecholamine production and oxygenrelated neurotransmitter release. The increase in HIF- $1 \alpha$ was dependent on the number of cycles of intermittent hypoxia and, although HIF- $1 \alpha$ is prone to rapid degradation upon reoxygenation, its degradation after 4 min of oxygenation was not detected. BERRA et al. [75] showed similar results with persistence of HIF- $1 \alpha$ after $5 \mathrm{~min}$ of reoxygenation in CCL39 cells, an established line of lung fibroblasts.

\section{In vivo studies}

The most robust data supporting a role for HIF-1 $\alpha$ in oxygen sensing by the carotid body come from mice partially deficient in HIF- $1 \alpha$ expression. Complete HIF- $1 \alpha$ deficiency is lethal at the embryonic stage of development, but hif $1 a^{+/-}$heterozygous (HET) mice develop normally [76]. Carotid body-mediated cardiorespiratory changes in response to intermittent hypoxia are absent or markedly attenuated in HET mice [77]. The impaired physiological responses to intermittent hypoxia in HET mice are associated with the absence of HIF-1 $\alpha$ upregulation and increased reactive oxygen species generation. HET mice do not develop hypertension in response to intermittent hypoxia in contrast to their wild-type litter-mates who develop hypertension and show increased HIF-1 expression within their carotid bodies [78].

LAM et al. [79] recently demonstrated increased rat carotid body expression of the HIF- $2 \alpha$ and HIF- $3 \alpha$ subtypes in response to intermittent hypoxia, in contrast to the increase in the HIF- $1 \alpha$ subtype seen in sustained hypoxia. The authors concluded that differential regulation of the HIF- $\alpha$ subtypes could account for the differences in carotid body responses to intermittent and sustained hypoxia.

A number of studies involving various animal models of intermittent hypoxia have examined its effect on carotid body function. FLETCHER and co-workers [80, 81] developed a rat model of intermittent hypoxia similar to the pattern seen in OSAS $(20 \mathrm{~s}$ of $5 \%$ inspiratory oxygen fraction; 9 episodes $\cdot \mathrm{h}^{-1} ; 8 \mathrm{~h} \cdot$ day $^{-1}$; 30 days) in which the animals developed hypertension and increased sympathetic nerve activity following exposure to intermittent hypoxia, and obliteration of this response occurred following denervation of the carotid bodies. REY et al. [82] have shown a reduction in baroreflex sensitivity in normotensive cats similar to that seen in OSAS patients following stimulation of the carotid bodies by intermittent hypoxia. PAWAR et al. [83] have demonstrated differences in carotid body responses to intermittent hypoxia between neonatal and adult rats. The data obtained by PAWAR et al. [83] suggested that neonatal carotid bodies are more sensitive to intermittent hypoxia than adult carotid bodies and that intermittent hypoxia stimulates glomus cell hyperplasia in neonatal carotid bodies. In contrast to adult carotid bodies, hypoxic sensitisation was not reversed in neonatal carotid bodies after re-exposure to normoxia.

In brief, the carotid body plays an important role in the perception of oxygen tension in intermittent hypoxia. The subsequent responses to intermittent hypoxia mediated by the carotid body differ to those provoked by sustained hypoxia and appear to be largely dependent on HIF-1 $\alpha$. Further work is required in this area, however, to define the downstream molecular mechanisms involved in the pathogenesis of cardiovascular comorbidities associated with intermittent hypoxia.

\section{Intermittent hypoxia and endothelial cells}

In vitro studies

A limited number of studies have examined the effects of intermittent hypoxia in endothelial cell culture models. RYAN et al. [46]

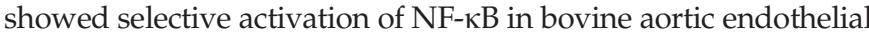
cells in response to intermittent hypoxia and proposed that this activation was dependent on p38 map kinase activation using data from a similar HeLa cell in vitro model. In contrast, intermittent hypoxia did not lead to significant HIF-1 activation, while sustained hypoxia led to a robust HIF-1 response.

Although HIF-1 $\alpha$ is unstable in normoxia (and consequently during the reoxygenation phase of intermittent hypoxia), there is evidence to support modulation of HIF-1 $\alpha$ expression in endothelial cells by intermittent hypoxia in vitro. However, it should be noted that these studies investigated the effects of intermittent hypoxia in the context of vascularised tumours rather than OSAS and, therefore, their relevance to OSAS is unknown. TOFFOLI et al. [84] showed a progressive increase in HIF- $1 \alpha$ during the hypoxic phases of intermittent hypoxia $(1 \mathrm{~h}$ of $1 \% \mathrm{O}_{2}$ alternating with $30 \mathrm{~min} 20 \% \mathrm{O}_{2}$ ) in two endothelial cell lines, EAhy926 and human microvascular endothelial cell-1. As HIF-1 $\alpha$ was degraded during the normoxic phase of these cycles, it appears that enhanced HIF-1 $\alpha$ stabilisation occurred with intermittent hypoxia in each hypoxic period, although the mechanism of this stabilisation is not apparent. This observation has also been made in human umbilical vein endothelial cells [85]. Progressive increases in the phosphorylated form of HIF-1 $\alpha$ also occurred in endothelial cells in a protein kinase (PK)A-dependent manner in response to intermittent hypoxia, and HIF- $1 \alpha$ transcriptional activity was reduced by PKA inhibition [84]. The physiological relevance of this progressive HIF- $1 \alpha$ phosphorylation remains unclear.

\section{Clinical studies}

The endothelium forms an $\sim 1-\mathrm{kg}$ functional organ in the adult human and its position at the interface of tissues and circulating blood makes it readily susceptible to the effects of intermittent hypoxia [86]. The endothelium shows little evidence of disturbance to its integrity in the absence of disease. If specifically looked for, apoptotic endothelial cells 
are rarely found in the intima of normal blood vessels [87]. It is proposed that apoptotic cells play an early role in the development of endothelial dysfunction and atherosclerosis and known cardiac risk factors increase endothelial apoptosis in vitro and in vivo [86]. Apoptotic endothelial cells have also been shown in experimental and human atherosclerotic plaques [87-89]. These cells also release IL-1 which can activate $\mathrm{NF}-\kappa \mathrm{B}$ in neighbouring endothelial cells, thereby increasing pro-inflammatory cytokine production (TNF- $\alpha$ and IL-8) and promoting leukocyte adhesion molecule expression and release [91].

EL SOLH et al. [91] demonstrated that OSAS patients have increased number of circulating apoptotic endothelial cells compared with non-OSAS controls, and that levels correlated with abnormal brachial artery flow-mediated dilation, a marker of endothelial dysfunction. The number of apoptotic endothelial cells in the circulation was lowered by therapy with nasal CPAP. However, contrasting results were reported in another recent study [92].

There is evidence that circulating endothelial progenitor cells (EPCs) derived from bone marrow are involved in the repair of damaged blood vessels and decreased levels of EPCs have been found to be predictive of future cardiovascular events in coronary artery disease. While lower numbers of EPCs have been noted in OSAS patients [93,94], one study has shown no statistical difference in either circulating endothelial cells or circulating EPCs in a group of OSAS patients, free of preexisting vascular disease, compared with age- and weightmatched controls [92].

\section{Intermittent hypoxia and white adipose tissue}

Qualifying the mechanisms which underlie the relationship between OSAS and the pathogenesis of cardiovascular disease is difficult in OSAS patient populations, owing to the extensive range of co-existing recognised cardiovascular risk factors, in particular obesity. There is a two-fold increase in the risk of developing OSAS with every $10 \mathrm{~kg}$ increase in body weight and a four-fold increase in risk with every $6 \mathrm{~kg} \cdot \mathrm{m}^{-2}$ increase in BMI [95]. In recent years, white adipose tissue has emerged as a major secretory organ, to such an extent that, in the obese, adipose tissue is often the largest endocrine organ. Obesity induces a chronic low-grade inflammatory state and many of the inflammatory pathways proposed to be activated by intermittent hypoxia in OSAS are also activated in adipose tissue. Adipose tissue expresses high levels of inflammatory cytokines, such as TNF- $\alpha$ and IL-6 [96-98]. Induction of these inflammatory cytokines in adipose tissue can also have further downstream metabolic effects often associated with OSAS. For example, changes in TNF- $\alpha$ associated with obesity can induce subsequent changes in insulin sensitivity and glucose homeostasis [99].

Rather than being mutually exclusive contributors to systemic inflammation, OSAS-related intermittent hypoxia may actually modify inflammatory cytokine production by white adipose tissue. It has been hypothesised that white adipose tissue is poorly oxygenated in the obese and that relative hypoxia develops within groups of adipocytes that have become distant from the vasculature with growth of the adipose tissue mass, leading to dysregulation of inflammatory adipokine production $[100,101]$. However, the limited number of studies to date exploring this hypothesis have focussed mainly on the effects of sustained hypoxia rather than intermittent hypoxia. As obesity is closely associated with OSAS, intermittent hypoxia may be of greater relevance to adipokine metabolism than sustained hypoxia, although further studies are required in this area.

\section{In vitro/in vivo studies}

A number of studies have examined adipokine production in OSAS but, as mentioned previously, there is a paucity of translational studies examining the effects of intermittent hypoxia per se on adipose tissue. Adiponectin (APN), the most abundant adipokine, is secreted exclusively by adipocytes, possesses anti-atherogenic properties, and low levels are associated with increased cardiovascular risk. Levels of APN are inversely correlated with the proportion of body fat in adults. 3T3-L1 adipocytes exposed to intermittent hypoxia for $48 \mathrm{~h}$ had a significant decrease in the secretion of total and high-molecular-weight APN compared with control adipocytes maintained in $21 \% \mathrm{O}_{2}$ under identical conditions [102]. NAKAGAWA et al. [103] demonstrated lower levels of circulating APN in patients with severe OSAS and sustained hypoxia reduced APN concentrations in C57BL/6J mice and 3T3-L1 adipocytes.

\section{Clinical studies}

Several other studies have demonstrated lower levels of APN in OSAS patients and subsequent improvement following CPAP therapy [104-110]. However, not all studies have shown an association between OSAS and APN [111-115]. WoLK et al. [116] showed that patients with OSAS had significantly higher plasma APN levels compared with non-OSAS BMI-matched controls, concluding that low APN levels are unlikely to account for the association between OSAS and cardiovascular disease.

It is also still unclear whether OSAS is independently associated with increased levels of the acute-phase reactant C-reactive protein (CRP). A number of studies have examined this question, demonstrating elevated levels of CRP associated with OSAS, but many have been limited by methodologies used, failing to properly control for BMI, and including patients with established cardiovascular and/or metabolic disease [117-120]. In contrast, when patients are groupmatched for BMI, free of co-morbidities and of similar sex, age, smoking status and lipid profile, an independent relationship was identified between CRP levels and BMI, but not with severity of OSAS [121]. Therefore, in OSAS, the data suggest that CRP levels correlate with adipose tissue mass and obesity rather than OSAS, an observation readily supported by the mechanisms of CRP production.

CRP is synthesised mainly in the liver under the regulation of IL-6, although IL-1 and TNF- $\alpha$ can also induce hepatic CRP mRNA expression. However, CRP production may be augmented by adipose tissue in two ways. First, CRP production has also been demonstrated in adipose tissue, although more weakly than in hepatic tissue. However, adipose tissue forms a much larger organ than the liver in obese individuals and the contribution of adipose-derived CRP is, therefore, probably of greater significance in obesity than in normal subjects. Secondly, adipose tissue is a major contributor to IL-6 production in the body, thereby further enhancing hepatic 


\section{TABLE 1 Tissue-specific effects of intermittent hypoxia}

\begin{tabular}{|c|c|c|}
\hline Tissue & Mechanism & Effects \\
\hline Carotid body & Oxygen sensing by HIF- $1 \alpha$ & $\begin{array}{l}\text { Enhanced sympathetic activity } \\
\text { Increased blood pressure } \\
\text { Decreased baroreflex sensitivity }\end{array}$ \\
\hline Endothelium & Activation of $\mathrm{NF}-\kappa \mathrm{B}$ & $\begin{array}{l}\text { Inflammatory cytokine production } \\
\text { Surface adhesion molecule expression } \\
\text { Increased apoptotic endothelial cells? } \\
\text { Decreased circulating endothelial progenitor cells? }\end{array}$ \\
\hline Adipose tissue & Activation of $\mathrm{NF}-\mathrm{\kappa B}$ & Dysregulation of adipokine production \\
\hline
\end{tabular}

CRP production. Thus, although CRP levels are elevated in OSAS patients, this probably reflects obesity and increased adipose tissue mass, rather than an effect of intermittent hypoxia.

In summary, OSAS is associated with a low-grade inflammatory state and a role may also exist for OSAS-related intermittent hypoxia in the modulation of adipose tissue cytokine metabolism. There are also noticeable differences apparent in the response to intermittent hypoxia between body tissues (table 1). HIF-1 plays a key role in oxygen-sensing by the carotid bodies and subsequent carotid body-mediated cardiovascular responses. In contrast, NF- $\kappa \mathrm{B}$ appears to be primarily responsible for inflammatory signalling by endothelial cells in OSAS. It is likely that NF- $\kappa B$ may also regulate inflammatory signalling in the adipose tissue of OSAS patients. A greater understanding of the mechanisms controlling these transcription factors and the cross-talk between them will provide new avenues of therapeutic opportunity for the condition.

\section{THERAPEUTIC POTENTIAL}

Currently, CPAP treatment is the mainstay of OSAS therapy. It effectively ameliorates the symptoms of the disease and reduces the associated long-term cardiovascular morbidity and mortality [10]. However, many patients stop using it because of discomfort and compliance rates vary [122, 123]. Current therapeutic alternatives to CPAP therapy are often suboptimal, particularly for patients with severe disease. Therefore, scope exists for the development and utilisation of therapeutic modalities directed toward the attenuation of inflammatory mechanisms in OSAS. VGONTZAS et al. [32] have already demonstrated that the TNF- $\alpha$ antagonist etanercept effectively reduced daytime sleepiness in a small cohort of OSAS patients. Research into agents which modulate the NF- $\kappa$ B and HIF-1 pathways may lead to novel treatment strategies and improved cardiovascular outcomes for OSAS patients in the future.

\section{CONCLUSION}

Obstructive sleep apnoea syndrome is a common medical disorder that is growing in prevalence worldwide. It is characterised by recurrent cycles of intermittent hypoxia and there is increasing evidence that intermittent hypoxia plays a role in the development of cardiovascular risk in obstructive sleep apnoea syndrome patients through the activation of inflammatory pathways. Scope exists for further studies demonstrating a direct linkage between inflammation and markers of atherosclerosis and cardiovascular disease in obstructive sleep apnoea syndrome, as currently only one study exists in the field [40]. The hypoxia-sensitive transcription factors hypoxia-inducible factor- 1 and nuclear factor- $\kappa \mathrm{B}$ appear to play a key role in mediating the inflammatory and cardiovascular consequences of the disease. Expanding our understanding of these pathways, the interaction between them and the potentiation of inflammation by intermittent hypoxia will yield novel therapeutic targets with the scope to reduce cardiovascular risk in obstructive sleep apnoea syndrome.

\section{REFERENCES}

1 Young T, Palta M, Dempsey J, Skatrud J, Weber S, Badr S. The occurrence of sleep-disordered breathing among middle-aged adults. N Engl J Med 1993; 328: 1230-1235.

2 Marshall NS, Wong KK, Liu PY, Cullen SR, Knuiman MW, Grunstein RR. Sleep apnea as an independent risk factor for all-cause mortality: the Busselton Health Study. Sleep 2008; 31: 1079-1085.

3 Young T, Finn L, Peppard PE, et al. Sleep disordered breathing and mortality: eighteen-year follow-up of the Wisconsin sleep cohort. Sleep 2008; 31: 1071-1078.

4 Nieto FJ, Young TB, Lind BK, et al. Association of sleepdisordered breathing, sleep apnea, and hypertension in a large community-based study. Sleep Heart Health Study. JAMA 2000; 283: 1829-1836.

5 Bixler EO, Vgontzas AN, Lin HM, et al. Association of hypertension and sleep-disordered breathing. Arch Intern Med 2000; 160: 2289-2295.

6 Peker Y, Kraiczi H, Hedner J, Löth S, Johansson A, Bende M. An independent association between obstructive sleep apnoea and coronary artery disease. Eur Respir J 1999; 14: 179-184.

7 Yaggi HK, Concato J, Kernan WN, Lichtman JH, Brass LM, Mohsenin V. Obstructive sleep apnea as a risk factor for stroke and death. $N$ Engl J Med 2005; 353: 2034-2041. 
8 Gami AS, Pressman G, Caples SM, et al. Association of atrial fibrillation and obstructive sleep apnea. Circulation 2004; 110: 364-367.

9 Wang H, Parker JD, Newton GE, et al. Influence of obstructive sleep apnea on mortality in patients with heart failure. J Am Coll Cardiol 2007; 49: 1625-1631.

10 Doherty LS, Kiely JL, Swan V, McNicholas WT. Longterm effects of nasal continuous positive airway pressure therapy on cardiovascular outcomes in sleep apnea syndrome. Chest 2005; 127: 2076-2084.

11 Marin JM, Carrizo SJ, Vicente E, Agusti AG. Long-term cardiovascular outcomes in men with obstructive sleep apnoea-hypopnoea with or without treatment with continuous positive airway pressure: an observational study. Lancet 2005; 365: 1046-1053.

12 McNicholas WT, Bonsignore MR, the Management Committee of ECAB. Sleep apnoea as an independent risk factor for cardiovascular disease: current evidence, basic mechanisms and research priorities. Eur Respir J 2007; 29: 156-178.

13 Caples SM, Gami AS, Somers VK. Obstructive sleep apnea. Ann Intern Med 2005; 142: 187-197.

14 Williams A, Scharf SM. Obstructive sleep apnea, cardiovascular disease and inflammation - is NF- $\kappa B$ the key? Sleep Breath 2007; 11: 69-76.

15 Krieger J, Sforza E, Boudewijns A, Zamagni M, Petiau C. Respiratory effort during obstructive sleep apnea: role of age and sleep state. Chest 1997; 112: 875-884.

16 Ryan S, Taylor C, McNicholas W. Selective activation of inflammatory pathways by intermittent hypoxia in obstructive sleep apnea syndrome. Circulation 2005; 112: 2660-2667.

17 Cahan C, Decker M, Strohl KP. Humoral correlates of sleep apnea: erythropoietin and hypoxemia. Prog Clin Biol Res 1990; 345: 317-322.

18 Cahan C, Decker MJ, Arnold JL, et al. Diurnal variations in serum erythropoietin levels in healthy subjects and sleep apnea patients. J Appl Physiol 1992; 72: 2112-2117.

19 Winnicki M, Shamsuzzaman A, Lanfranchi $\mathrm{P}$, et al. Erythropoietin and obstructive sleep apnea. Am J Hypertens 2004; 17: 783-786.

20 Imagawa S, Yamaguchi Y, Higuchi M, et al. Levels of vascular endothelial growth factor are elevated in patients with obstructive sleep apnea-hypopnea syndrome. Blood 2001; 98: 1255-1257.

21 Schulz R, Hummel C, Heinemann S, Seeger W, Grimminger F. Serum levels of vascular endothelial growth factor are elevated in patients with obstructive sleep apnea and severe nighttime hypoxia. Am J Respir Crit Care Med 2002; 165: 67-70.

22 Lavie L, Kraiczi H, Hefetz A, Ghandour H, Perelman A, Hedner J, Lavie P. Plasma vascular endothelial growth factor in sleep apnea syndrome: effects of nasal continuous positive air pressure treatment. Am J Respir Crit Care Med 2002; 165: 1624-1628.

23 Lavie L, Lavie P. Ischemic preconditioning as a possible explanation for the age decline relative mortality in sleep apnea. Med Hypotheses 2006; 66: 1069-1073.

24 Lavie P, Lavie L, Herer P. All-cause mortality in males with sleep apnoea syndrome: declining mortality rates with age. Eur Respir J 2005; 25: 514-520.
25 He J, Kryger MH, Zorick FJ, Conway W, Roth T. Mortality and apnea index in obstructive sleep apnea. Experience in 385 male patients. Chest 1988; 94: 9-14.

26 Lavie P, Herer P, Peled R, Berger I, Yoffe N, Zomer J, Rubin AH. Mortality in sleep apnea patients: a multivariate analysis of risk factors. Sleep 1995; 18: 149-157.

27 Marti S, Sampol G, Munoz X, et al. Mortality in severe sleep apnoea/hypopnoea syndrome patients: impact of treatment. Eur Respir J 2002; 20: 1511-1518.

28 Foster GE, Poulin MJ, Hanly PJ. Intermittent hypoxia and vascular function: implications for obstructive sleep apnoea. Exp Physiol 2007; 92: 51-65.

29 Dyugovskaya L, Lavie P, Lavie L. Phenotypic and functional characterization of blood $\gamma \delta \mathrm{T}$ cells in sleep apnea. Am J Respir Crit Care Med 2003; 168: 242-249.

30 Minoguchi K, Tazaki T, Yokoe T, et al. Elevated production of tumor necrosis factor- $\alpha$ by monocytes in patients with obstructive sleep apnea syndrome. Chest 2004; 126: 1473-1479.

31 Vgontzas AN, Papanicolaou DA, Bixler EO, Kales A, Tyson K, Chrousos GP. Elevation of plasma cytokines in disorders of excessive daytime sleepiness: role of sleep disturbance and obesity. J Clin Endocrinol Metab 1997; 82: 1313-1316.

32 Vgontzas AN, Zoumakis E, Lin HM, Bixler EO, Trakada G, Chrousos GP. Marked decrease in sleepiness in patients with sleep apnea by etanercept, a tumor necrosis factor- $\alpha$ antagonist. J Clin Endocrinol Metab 2004; 89: 4409-4413.

33 Ryan S, Taylor C, McNicholas W. Predictors of elevated nuclear factor- $\kappa \mathrm{B}-$ dependent genes in obstructive sleep apnea syndrome. Am J Respir Crit Care Med 2006; 174: 824-830.

34 Imagawa S, Yamaguchi Y, Ogawa K, et al. Interleukin-6 and tumor necrosis factor- $\alpha$ in patients with obstructive sleep apnea-hypopnea syndrome. Respiration 2004; 71: 24-29.

35 Dyugovskaya L, Polyakov A, Lavie P, Lavie L. Delayed neutrophil apoptosis in patients with sleep apnea. Am J Respir Crit Care Med 2008; 177: 544-554.

36 Dyugovskaya L, Lavie P, Lavie L. Increased adhesion molecules expression and production of reactive oxygen species in leukocytes of sleep apnea patients. Am J Respir Crit Care Med 2002; 165: 934-939.

37 Dyugovskaya L, Lavie P, Hirsh M, Lavie L. Activated CD8+ T-lymphocytes in obstructive sleep apnoea. Eur Respir J 2005; 25: 820-828.

38 Dyugovskaya L, Lavie P, Lavie L. Lymphocyte activation as a possible measure of atherosclerotic risk in patients with sleep apnea. Ann N Y Acad Sci 2005; 1051: 340-350.

39 Lavie L, Dyugovskaya L, Lavie P. Sleep-apnea-related intermittent hypoxia and atherogenesis: adhesion molecules and monocytes/endothelial cells interactions. Atherosclerosis 2005; 183: 183-184.

40 Minoguchi K, Yokoe T, Tazaki T, et al. Increased carotid intima-media thickness and serum inflammatory markers in obstructive sleep apnea. Am J Respir Crit Care Med 2005; 172: 625-630.

41 Sen $R$, Baltimore D. Inducibility of $\kappa$ immunoglobulin enhancer-binding protein NF- $\kappa \mathrm{B}$ by a posttranslational mechanism. Cell 1986; 47: 921-928. 
42 Karin M. Nuclear factor- $\kappa \mathrm{B}$ in cancer development and progression. Nature 2006; 441: 431-436.

43 Greenberg H, Ye X, Wilson D, Htoo AK, Hendersen T, Liu SF. Chronic intermittent hypoxia activates nuclear factor- $\mathrm{KB}$ in cardiovascular tissues in vivo. Biochem Biophys Res Commun 2006; 343: 591-596.

44 Kletsas D, Pratsinis H, Mariatos G, Zacharatos P, Gorgoulis VG. The proinflammatory phenotype of senescent cells: the p53-mediated ICAM-1 expression. Ann N Y Acad Sci 2004; 1019: 330-332.

45 Tsatsanis C, Androulidaki A, Venihaki M, Margioris AN. Signalling networks regulating cyclooxygenase-2. Int $J$ Biochem Cell Biol 2006; 38: 1654-1661.

46 Ryan S, McNicholas WT, Taylor CT. A critical role for p38 map kinase in NF- $\mathrm{B}$ signaling during intermittent hypoxia/reoxygenation. Biochem Biophys Res Commun 2007; 355: 728-733.

47 Htoo AK, Greenberg H, Tongia S, et al. Activation of nuclear factor- $\kappa \mathrm{B}$ in obstructive sleep apnea: a pathway leading to systemic inflammation. Sleep Breath 2006; 10: 43-50.

48 Semenza G. Hydroxylation of HIF-1: oxygen sensing at the molecular level. Physiology 2004; 19: 176-182.

49 Huang LE, Gu J, Schau M, Bunn HF. Regulation of hypoxia-inducible factor $1 \alpha$ is mediated by an $\mathrm{O}_{2-}$ dependent degradation domain via the ubiquitin-proteasome pathway. Proc Natl Acad Sci USA 1998; 95: 7987-7992.

50 Papandreou I, Cairns RA, Fontana L, Lim AL, Denko NC. HIF-1 mediates adaptation to hypoxia by actively downregulating mitochondrial oxygen consumption. Cell Metab 2006; 3: 150-151.

51 Fandrey J. Oxygen-dependent and tissue-specific regulation of erythropoietin gene expression. Am J Physiol Regul Integr Comp Physiol 2004; 286: R977-R988.

52 Cummins EP, Taylor CT. Hypoxia-responsive transcription factors. Pflugers Arch 2005; 450: 363-371.

53 Yuan G, Nanduri J, Bhasker CR, Semenza GL, Prabhakar NR. $\mathrm{Ca}^{2+} /$ calmodulin kinase-dependent activation of hypoxia inducible factor 1 transcriptional activity in cells subjected to intermittent hypoxia. J Biol Chem 2005; 280: 4321-4328.

54 Yuan G, Nanduri J, Khan S, Semenza GL, Prabhakar NR. Induction of HIF-1 $\alpha$ expression by intermittent hypoxia: involvement of NADPH oxidase, $\mathrm{Ca}^{2+}$ signaling, prolyl hydroxylases, and mTOR. J Cell Physiol 2008; 217: 674-685.

55 Cramer T, Yamanishi Y, Clausen BE, et al. HIF- $1 \alpha$ is essential for myeloid cell-mediated inflammation. Cell 2003; 112: 645-657.

56 Rius J, Guma M, Schachtrup C, et al. NF-кB links innate immunity to the hypoxic response through transcriptional regulation of HIF-1 $\alpha$. Nature 2008; 453: 807-811.

57 van Uden P, Kenneth NS, Rocha S. Regulation of hypoxia-inducible factor- $1 \alpha$ by NF- $\kappa$ B. Biochem J 2008; 412: 477-484.

58 Belaiba RS, Bonello S, Zähringer C, et al. Hypoxia upregulates hypoxia-inducible factor- $1 \alpha$ transcription by involving phosphatidylinositol 3-kinase and nuclear factor $\mathrm{\kappa B}$ in pulmonary artery smooth muscle cells. Mol Biol Cell 2007; 18: 4691-4697.
59 Walmsley SR, Print C, Farahi N, et al. Hypoxia-induced neutrophil survival is mediated by HIF-1 $\alpha$-dependent NF- $\kappa$ B activity. J Exp Med 2005; 201: 105-115.

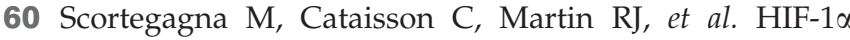
regulates epithelial inflammation by cell autonomous $\mathrm{NF} \kappa \mathrm{B}$ activation and paracrine stromal remodeling. Blood 2008; 111: 3343-3354.

61 Xie QW, Kashiwabara Y, Nathan C. Role of transcription factor NF- $\kappa \mathrm{B} /$ Rel in induction of nitric oxide synthase. J Biol Chem 1994; 269: 4705-4708.

62 Jung F, Palmer LA, Zhou N, Johns RA. Hypoxic regulation of inducible nitric oxide synthase via hypoxia inducible factor-1 in cardiac myocytes. Circ Res 2000; 86: 319-325.

63 Taylor CT. Interdependent roles for hypoxia inducible factor and nuclear factor- $\mathrm{\kappa B}$ in hypoxic inflammation. J Physiol 2008; 586: 4055-4059.

64 Robbins P. Role of the peripheral chemoreflex in the early stages of ventilatory acclimatization to altitude. Respir Physiol Neurobiol 2007; 158: 237-242.

65 Serebrovskaya TV, Manukhina EB, Smith ML, Downey HF, Mallet RT. Intermittent hypoxia: cause of or therapy for systemic hypertension? Exp Biol Med (Maywood) 2008; 233: 627-650.

66 Küpper T, Schöffl V, Netzer N. Cheyne Stokes breathing at high altitude: a helpful response or a troublemaker? Sleep Breath 2008; 12: 123-127.

67 Marticorena E, Ruiz L, Severino J, Galvez J, Peñaloza D. Systemic blood pressure in white men born at sea level: changes after long residence at high altitudes. Am J Cardiol 1969; 23: 364-368.

68 Mortimer EA Jr, Monson RR, MacMahon B. Reduction in mortality from coronary heart disease in men residing at high altitude. $N$ Engl J Med 1977; 296: 581-585.

69 Powell F. The influence of chronic hypoxia upon chemoreception. Respir Physiol Neurobiol 2007; 157: 154-161.

70 Narkiewicz K, van de Borne PJ, Cooley RL, Dyken ME, Somers VK. Sympathetic activity in obese subjects with and without obstructive sleep apnea. Circulation 1998; 98: 772-776.

71 Narkiewicz K, van de Borne PJ, Montano N, Dyken ME, Phillips BG, Somers VK. Contribution of tonic chemoreflex activation to sympathetic activity and blood pressure in patients with obstructive sleep apnea. Circulation 1998; 97: 943-945.

72 Narkiewicz K, van de Borne PJ, Pesek CA, Dyken ME, Montano N, Somers VK. Selective potentiation of peripheral chemoreflex sensitivity in obstructive sleep apnea. Circulation 1999; 99: 1183-1189.

73 Ryan S, Ward S, Heneghan C, McNicholas WT Predictors of decreased spontaneous baroreflex sensitivity in obstructive sleep apnea syndrome. Chest 2007; 131: 1100-1107.

74 Semenza G. Regulation of physiological responses to continuous and intermittent hypoxiaby hypoxia-inducible factor 1. Exp Physiol 2006; 91: 803-806.

75 Berra E, Milanini J, Richard DE, et al. Signaling angiogenesis via p42/p44 MAP kinase and hypoxia. Biochem Pharmacol 2000; 60: 1171-1178. 
76 Yu AY, Shimoda LA, Iyer NV, et al. Impaired physiological responses to chronic hypoxia in mice partially deficient for hypoxia-inducible factor $1 \alpha$. J Clin Invest 1999; 103: 691-696.

77 Peng YJ, Yuan G, Ramakrishnan D, et al. Heterozygous HIF-1alpha deficiency impairs carotid body-mediated systemic responses and reactive oxygen species generation in mice exposed to intermittent hypoxia. J Physiol 2006; 577: 705-716.

78 Semenza GL, Prabhakar N. HIF-1-dependent respiratory, cardiovascular, and redox responses to chronic intermittent hypoxia. Antioxid Redox Signal 2007; 9: 1391-1396.

79 Lam SY, Tipoe GL, Liong EC, Fung ML. Differential expressions and roles of hypoxia-inducible factor- $1 \alpha,-2 \alpha$ and $-3 \alpha$ in the rat carotid body during chronic and intermittent hypoxia. Histol Histopathol 2008; 23: 271-280.

80 Fletcher EC, Lesske J, Behm R, Miller CC 3rd, Stauss H, Unger T., Carotid chemoreceptors, systemic blood pressure, and chronic episodic hypoxia mimicking sleep apnea. J Appl Physiol 1992; 72: 1978-1984.

81 Lesske J, Fletcher EC, Bao G, Unger T. Hypertension caused by chronic intermittent hypoxia--influence of chemoreceptors and sympathetic nervous system. J Hypertens 1997; 15: 1593-1603.

82 Rey S, Del Rio R, Alcayaga J, Iturriaga R. Chronic intermittent hypoxia enhances cat chemosensory and ventilatory responses to hypoxia. J Physiol 2004; 560: 577-586.

83 Pawar A, Peng YJ, Jacono FJ, Prabhakar NR. Comparative analysis of neonatal and adult rat carotid body responses to chronic intermittent hypoxia. J Appl Physiol 2008; 104: 1287-1294.

84 Toffoli S, Feron O, Raes M, Michiels C. Intermittent hypoxia changes HIF-1 $\alpha$ phosphorylation pattern in endothelial cells: unravelling of a new PKA-dependent regulation of HIF-1 $\alpha$. Biochim Biophys Acta 2007; 773: 1558-1571.

85 Martinive P, Defresne F, Bouzin C, et al. Preconditioning of the tumor vasculature and tumor cells by intermittent hypoxia: implications for anticancer therapies. Cancer Res 2006; 66: 11736-11744.

86 Stefanec T. Endothelial apoptosis: could it have a role in the pathogenesis and treatment of disease? Chest 2000; 117: 841-854.

87 Alvarez RJ, Gips SJ, Moldovan N, et al. 17ß-estradiol inhibits apoptosis of endothelial cells. Biochem Biophys Res Commun 1997; 237: 372-381.

88 Haunstetter A, Izumo S. Apoptosis: basic mechanisms and implications for cardiovascular disease. Circ Res 1998; 82: 1111-1129.

89 Hasdai D, Sangiori G, Spagnoli LG, et al. Coronary artery apoptosis in experimental hypercholesterolemia. Atherosclerosis 1999; 142: 317-325.

90 Barnes PJ, Karin M. Nuclear factor $\kappa B$ : a pivotal transcription factor in chronic inflammatory diseases. $N$ Engl J Med 1997; 336: 1066-1071.

91 El Solh AA, Akinnusi ME, Baddoura FH, Mankowski CR. Endothelial cell apoptosis in obstructive sleep apnea: a link to endothelial dysfunction. Am J Respir Crit Care Med 2007; 175: 1186-1191.
92 Martin K, Stanchina M, Kouttab N, Harrington EO, Rounds S. Circulating Endothelial cells and endothelial progenitor cells in obstructive sleep apnea. Lung 2008; 186: $145-150$.

93 Jelic S, Padeletti M, Kawut SM, et al. Inflammation, oxidative stress, and repair capacity of the vascular endothelium in obstructive sleep apnea. Circulation 2008; 117: 2270-2278.

94 de la Peña M, Barceló A, Barbe F, et al. Endothelial function and circulating endothelial progenitor cells in patients with sleep apnea syndrome. Respiration 2008; 76: 28-32.

95 Wolk R, Somers VK. Sleep and the metabolic syndrome. Exp Physiol 2007; 92: 67-78.

96 Hotamisligil GS, Speigelman BM. Tumor necrosis factor $\alpha$ : a key component of the obesity-diabetes link. Diabetes 1994; 43: 1271-1278.

97 Mohamed-Ali V, Goodrick S, Rawesh A, et al. Subcutaneous adipose tissue releases interleukin-6, but not tumor necrosis factor- $\alpha$, in vivo. J Clin Endocrinol Metab 1997; 82: 4196-4200.

98 Coppack S. Pro-inflammatory cytokines and adipose tissue. Proc Nutr Soc 2001; 60: 349-356.

99 Ruan H, Lodish HF. Insulin resistance in adipose tissue: direct and indirect effects of tumor necrosis factor- $\alpha$. Cytokine Growth Factor Rev 2003; 14: 447-455.

100 Trayhurn P, Wood IS. Adipokines: inflammation and the pleiotropic role of white adipose tissue. Br J Nutr 2004; 92: 347-355.

101 Trayhurn P, Wang B, Wood IS. Hypoxia in adipose tissue: a basis for the dysregulation of tissue function in obesity? Br J Nutr 2008; 100: 227-235.

102 Magalang UJ, Cruff JP, Rajappan R, et al. Intermittent hypoxia suppresses adiponectin secretion by adipocytes. Exp Clin Endocrinol Diabetes 2008; [Epub ahead of print PMID: 18563681].

103 Nakagawa Y, Kishida K, Kihara S, et al. Nocturnal reduction in circulating adiponectin concentrations related to hypoxic stress in severe obstructive sleep apnea-hypopnea syndrome. Am J Physiol Endocrinol Metab 2008; 294: E778-E784.

104 Kanbay A, Kokturk O, Ciftci TU, Tavil Y, Bukan N. Comparison of serum adiponectin and tumor necrosis factor- $\alpha$ levels between patients with and without obstructive sleep apnea syndrome. Respiration 2008; 76: 324-330.

105 Takahashi K, Chin K, Nakamura H, et al. Plasma thioredoxin, a novel oxidative stress marker, in patients with obstructive sleep apnea before and after nasal continuous positive airway pressure. Antioxid Redox Signal 2008; 10: 715-726.

106 Zhang XL, Yin KS, Li C, Jia EZ, Li YQ, Gao ZF. Effect of continuous positive airway pressure treatment on serum adiponectin level and mean arterial pressure in male patients with obstructive sleep apnea syndrome. Chin Med J (Engl) 2007; 120: 1477-1481.

107 Masserini B, Morpurgo PS, Donadio F, et al. Reduced levels of adiponectin in sleep apnea syndrome. J Endocrinol Invest 2006; 29: 700-705.

108 Zhang XL, Yin KS, Wang H, Su S. Serum adiponectin levels in adult male patients with obstructive sleep apnea hypopnea syndrome. Respiration 2006; 73: 73-77. 
109 Harsch IA, Wallaschofski H, Koebnick C, et al. Adiponectin in patients with obstructive sleep apnea syndrome: course and physiological relevance. Respiration 2004; 71: 580-586.

110 Zhang XL, Yin KS, Mao H, Wang H, Yang Y. Serum adiponectin level in patients with obstructive sleep apnea hypopnea syndrome. Chin Med J (Engl) 2004; 117: 1603-1606.

111 Makino S, Handa H, Suzukawa K, et al. Obstructive sleep apnoea syndrome, plasma adiponectin levels, and insulin resistance. Clin Endocrinol (Oxf) 2006; 64: 12-19.

112 Sumi K, Chin K, Takahashi K, et al. Effect of nCPAP therapy on heart rate in patients with obstructive sleep apnoea-hypopnoea. QJM 2006; 99: 545-553.

113 Sharma SK, Kumpawat S, Goel A, Banga A, Ramakrishnan L, Chaturvedi P. Obesity, and not obstructive sleep apnea, is responsible for metabolic abnormalities in a cohort with sleep-disordered breathing. Sleep Med 2007; 8: 12-17.

114 Tauman R, Serpero LD, Capdevila OS, et al. Adipokines in children with sleep disordered breathing. Sleep 2007; 30: 443-449.

115 West SD, Nicoll DJ, Wallace TM, Matthews DR, Stradling JR. Effect of CPAP on insulin resistance and $\mathrm{HbA} 1 \mathrm{c}$ in men with obstructive sleep apnoea and type 2 diabetes. Thorax 2007; 62: 969-974.

116 Wolk R, Svatikova A, Nelson CA, et al. Plasma levels of adiponectin, a novel adipocyte-derived hormone, in sleep apnea. Obes Res 2005; 13: 186-190.
117 Yokoe T, Minoguchi K, Matsuo H, et al. Elevated levels of C-reactive protein and interleukin-6 in patients with obstructive sleep apnea syndrome are decreased by nasal continuous positive airway pressure. Circulation 2003; 107: 1129-1134.

118 Hayashi M, Fujimoto K, Urushibata K, Takamizawa A, Kinoshita O, Kubo K. Hypoxia-sensitive molecules may modulate the development of atherosclerosis in sleep apnoea syndrome. Respirology 2006; 11: 24-31.

119 Kokturk O, Cifci TU, Mollarecep E, Cifci B. Elevated Creactive protein levels and increased cardiovascular risk in patients with obstructive sleep apnea syndrome. Int Heart J 2005; 46: 801-809.

120 Saletu M, Nosiska D, Kapfhammer G, et al. Structural and serum surrogate markers of cerebrovascular disease in obstructive sleep apnea (OSA). Association of mild OSA with early atherosclerosis. J Neurol 2006; 253: 746-752.

121 Ryan S, Nolan GM, Hannigan E, Cunningham S, Taylor C, McNicholas WT. Cardiovascular risk markers in obstructive sleep apnoea syndrome and correlation with obesity. Thorax 2007; 62: 509-514.

122 McNicholas WT. Compliance with nasal CPAP therapy for obstructive sleep apnoea: how much is enough? Eur Respir J 1997; 10: 969-970.

123 Sin DD, Mayers I, Man GC, Pawluk L. Long-term compliance rates to continuous positive airway pressure in obstructive sleep apnea: a population-based study. Chest 2002; 121: 430-435. 